\title{
A Retrospective Cross Sectional Study of Clinical Characteristics and Prognostic Factors of Covid 19 Patients Admitted to a Gambian Teaching Hospital
}

Sheikh Omar Bittaye ( $\nabla$ sobittaye@utg.edu.gm )

Edward Francis Small Teaching Hospital

Abubacarr Jagne

Edward Francis Small Teaching Hospital

Abdoulie Badjan

Edward Francis Small Teaching Hospital

\section{Babakunta Fofana}

Edward Francis Small Teaching Hospital

\section{Ebrima Barrow}

Edward Francis Small Teaching Hospital

Ismaila Sonko

Edward Francis Small Teaching Hospital

Morikebba Danso

Edward Francis Small Teaching Hospital

\section{Ramatoulie Secka}

Edward Francis Small Teaching Hospital

\section{Landing Jarjue}

Edward Francis Small Teaching Hospital

\section{George Goddard}

Edward Francis Small Teaching Hospital

\section{Musa Cham}

Edward Francis Small Teaching Hospital

\section{Sainabou Sallah}

Edward Francis Small Teaching Hospital

\section{Sohna Joof}

Edward Francis Small Teaching Hospital

\section{Momodou Sohna}

Edward Francis Small Teaching Hospital

\section{Maimuna Danso}

Edward Francis Small Teaching Hospital

William Estrada 
Edward Francis Small Teaching Hospital

Julio Antonio Perez Ramos

Edward Francis Small Teaching Hospital

Marcos Antonio Sastre Acevedo

Edward Francis Small Teaching Hospital

\section{Federico Carlos Mendez}

Edward Francis Small Teaching Hospital

\section{Charles Adeyemi Roberts}

Edward Francis Small Teaching Hospital

\section{Mustapha Bittaye}

Edward Francis Small Teaching Hospital

\section{Ahmadou Samateh}

Edward Francis Small Teaching Hospital

\section{Ramatoulie Njie}

University of the Gambia

\section{Ousman Nyan}

Edward Francis Small Teaching Hospital

\section{Research Article}

Keywords: prognostic factors, Covid 19, patients, Gambian teaching hospital, cross sectional study

Posted Date: June 17th, 2021

DOI: https://doi.org/10.21203/rs.3.rs-603762/v1

License: (c) (1) This work is licensed under a Creative Commons Attribution 4.0 International License.

Read Full License 


\section{Abstract}

Background: The first case of Novel coronavirus disease (COVID 19) was diagnosed in The Gambia on the 17th March 2020. We therefore investigate the clinical characteristics and prognostic factors of COVID 19 patients admitted at a Gambian teaching Hospital.

Method: Out of 407 suspected COVID 19 patients, 137 (33.7\%) tested positive for COVID 19 and were recruited. Clinical features, treatment and outcomes were recorded. Univariate and multivariate logistic regression analyses were used to assess prognostic factors of survival in our patients.

Results: The median age of our patients was 60 years (19-100) and $86(62.8 \%)$ were men. Eighty nine (64.9\%) patients had co-morbidities, mostly Hypertension 51 (37.2\%) and Diabetes Mellitus 47 (34.3\%). The most common symptoms were cough $71(51.8 \%)$ and dyspnea $53(38.7 \%)$ and majority of patients presented with SPO $\leq 93 \% 75$ (54.7\%). Patients with SPO2 $\leq 93 \%$ were older 63.2 vs. 53.1 years $(p=0.001)$, more likely to present with dyspnea $(p=0.002)$, Cough $(0.035)$, higher respiratory rate $(p<0.001)$ and co-morbidities $(p=0.009)$ compared to patients with SPO2>93\%. Non survivors were older $63.2 \mathrm{vs}$ 53.1 years $(p=0.001)$, more likely to present with higher respiratory rate $(p=0.014)$, lower oxygen saturation $(p=<0.001)$, to be referred from lower level health facility $(p=0.012)$ and to have Diabetes mellitus ( $p=0.007)$ as compared to survivors. Our cumulative mortality is $49(35.8 \%)$ and mortality rate of patients referred from lower level heath facilities was $46 \%$ as compared to $25 \%$ for self referred patients. Multivariate analysis showed increasing odds of mortality independently associated with Age $\geq 60$ years (odd ratio, 2.87: $95 \% \mathrm{Cl}, 1.21$ to 6.83, $\mathrm{p}=0.012$ ), Diabetes mellitus (odd ratio, 3.47: 95\% $\mathrm{Cl}, 1.44$ to 8.36, $\mathrm{p}=0.006$ ), oxygen saturation $\leq 93 \%$ (odd ratio, 3.18 : $95 \% \mathrm{Cl}, 1.27$ to $7.99, p=0.014$ ) and referral from lower level health facility (odd ratio, 2.87: $95 \% \mathrm{Cl}, 1.11$ to $6.82, \mathrm{p}=0.017$ ).

Conclusion: Older patients, patients with Diabetes Mellitus, hypoxemia or patients referred from lower level health facilities are at increased risk of death. In resource limited countries where critical care/emergency medicine resources are limited, our results may help guide the clinical management of patients with severe COVID-19.

\section{Summary}

\section{WHAT IS ALREADY KNOWN ON THIS TOPIC}

Studies suggest that a majority of coronavirus disease 2019 (COVID-19) deaths have occurred among adults aged $\geq 60$ years and among persons with serious underlying health conditions.

\section{WHAT THIS STUDY ADDS}

This first preliminary description of outcomes among patients with COVID-19 in the Gambia indicates that hypoxemia (odd ratio, 3.18: $95 \% \mathrm{Cl}, 1.27$ to $7.99, \mathrm{p}=0.014$ ) and referrals from lower level health 
facilities (primary and secondary level) (odd ratio, 2.87: 95\% Cl, 1.11 to 6.82, p=0.017) are independent prognostic factors associated with mortality.

\section{WHAT ARE THE IMPLICATIONS FOR PUBLIC HEALTH PRACTICE?}

Referrals to tertiary facilities of suspected COVID-19 patients from lower level health facilities (primary and secondary) in resource limited countries are more likely to have a poorer outcome due to the limited critical care resources, lack of specialist, delay in testing and a weak referral system. Therefore there is need to improve our referral system, strengthen the critical care/emergency and testing facilities to help improve the care of COVID 19 patients.

\subsection{Introduction}

\section{Background}

COVID-19 is caused by a novel beta-coronavirus named severe acute respiratory syndrome coronavirus 2 (SARS-CoV-2) that was first reported in December 2019 in the city of Wuhan, Hubei province, China(1). On the 30th January 2020 World Health Organisation (WHO) declared COVID-19 as a public health emergency of global concern and Africa was the last continent to be hit by the virus. The continent confirmed its first case in Egypt on 14th of February, 2020, and from sub-Saharan Africa the first case was reported in Nigeria on 27th of February(2)'(3). The first case of COVID 19 was diagnosed in The Gambia on the 17th March 2020 and as of the 28th January 2021, we registered 4090 confirmed COVID 19 cases with 128 deaths.

The clinical presentation of COVID 19 ranges from mild infection to fatal illness. The most commonly reported symptoms were cough, fever and dyspnea. Critically ill patients were older, more likely to be male and have underlying co-morbidities. The mortality rate ranges from $8.7-21 \%$ among those patients admitted with pneumonia(4)'(5)'(6). In a larger report 49\% of all 2087 critically ill patients with COVID 19 in China died(7). Elderly patients with co-morbidities were found to be at greater risk of dying(8).

In Western countries, the reaction to the COVID-19 pandemic has been to increase hospital capacity and to provide more intensive care units (ICUs) and more ventilators. There had been little discussion of the provision of oxygen as this is a standard clinical tool widely available in hospitals. However in SubSaharan Africa (SSA) there is a shortage of oxygen in health facilities and thus two things should be atop of that list before ICUs and ventilators. These are personal protective equipment (PPE) for frontline health workers and oxygen for the patients(9)'(10). In The Gambia it is only our hospital that has a dedicated intensive care unit (ICU) with eight beds, making an estimated 0.4 ICU beds/100,000 population in the country. None of the lower level health facilities (primary or secondary) has a dedicated ICU ward and critical care resources are also limited. This very low ICU bed capacity and lack of human resources and equipment necessary to diagnose and treat the large number of critically ill patients admitted to public and private hospitals in the country(11).(12) may hinder the countries response to COVID 19. 


\section{RATIONAL/JUSTIFICATION}

COVID 19 is a pandemic of major public concern. Data on the clinical characteristics, co-morbidities and prognostic factors of COVID 19 patients admitted in The Gambia are scarce. We therefore assess the clinical features, co- morbidities and prognosis of COVID 19 patients admitted at Edward Francis Small Teaching Hospital in The Gambia. The morbidity and mortality data from this study will be of considerable value for the early identification of individuals who are at risk of becoming critically ill or dying and who are most likely to benefit from early screening and possible treatment.

\section{OBJECTIVE}

Goal - To identify prognostic risk factors for poor outcome among COVID 19 patients admitted to a tertiary facility in The Gambia

Objectives -

1. To describe the clinical features of COVID 19 patients admitted to a tertiary facility in The Gambia

2. To assess the prevalence of co-morbidities among COVID 19 patients admitted to a tertiary facility in The Gambia

3. To determine the prognostic risk factors for death among COVID 19 patients admitted to a tertiary facility in The Gambia

\subsection{Materials And Methods}

The study was conducted in the, Edward Francis Small Teaching Hospital (EFSTH), the main referral hospital in the capital city Banjul. The EFSTH has a total bed capacity of 500 and is only one of two Covid 19 treatment centres in the country. Using patient records from EFSTH we identified patients using the WHO case definition for Covid 19 patient: all laboratory confirmed patients with COVID 19 infection, irrespective of clinical signs and symptoms(13) between 2nd July and 28th February 2021. The single inclusion criterion of this retrospective study was a laboratory confirmed diagnosis of Covid 19. Any suspected Covid 19 patient with negative results, or unknown COVID 19 results and confirmed COVID 19 patients with incomplete data were excluded.

A total of 137 patients with Covid 19 were identified and included in this study (Fig. 1).

This study was approved by the Ethics Institutional Review Board of University of The Gambia (Research and Publication committee). However, informed patient consent was not required due to the retrospective nature of this study.

The following data were extracted from the patient's records: referral facility, demographic data (age and sex), co-morbidities (Hypertension Diabetes mellitus, Tuberculosis/Chronic obstructive pulmonary disease, Congestive heart failure, Chronic renal failure, Human immunodeficiency syndrome), symptoms (Cough, Dyspnoea, fever, Generalised body pains, Chest pain, sore throat), signs (Temperature, Systolic 
blood pressure, Diastolic blood pressure, Pulse, Oxygen saturation), disease severity as per WHO definition ${ }^{14}$ using oxygen saturation, treatment (Antibiotics, steroids, oxygen therapy) and clinical outcomes (Death, Discharged).

\section{Sample size determination}

In The Gambia, the average positivity of COVID 19 among our population is shown to be around $9 \%$. Therefore, the minimum sample size for simple proportion with $5 \%$ accuracy, and $95 \%$ level of confidence is calculated as below:

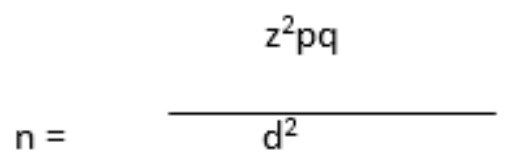

Where, $\mathrm{n}=$ Minimum sample size

$\mathrm{z}=$ the standard normal deviation usually set at 1.96

$p=$ highest quoted rate in environment

$q=1.0-P$

$d=$ degree of accuracy set at 0.05

Then, $\mathrm{n}=1.96 \times 1.96 \times 0.09 \times(1-0.09)$

$0.05 \times 0.05$

$=1.96 \times 1.96 \times 0.09 \times 0.91$

$0.05 \times 0.05$

$=125$

\subsection{Statistical analyses}

Statistical analysis were performed using the STATA/SE 12.1 statistics/Data analysis. Continuous data are presented as the mean \pm standard deviation and categorical data by number $(n)$ and percentage (\%). Mann-Whitney U-test and Students t-test were used to compare continuous variables and Chi-square test/ Fishers exact tests were used for discrete variables. Survival curves were determined from the Kaplan Meier method and differences between survival curves were examined using the log-rank test. All statistical assessments were two sided and $p<0.05$ was considered statistically significant. In all cases, survival analysis is calculated from the date of admission to the date of death. Statistical significance is defined as $p<0.05$. 


\subsection{Results}

\subsection{Clinical characteristics, co-morbidities and treatment}

Patient demographics and clinical characteristics are presented in Table 1. The median age of our patients at the time of diagnosis was 60 years and ranged between 19 to 100 years and $51.8 \%$ were 60 years or older. The disease affected males $86(62.8 \%)$ more than females $51(37.2 \%)$ and males were older (61 vs. 50 years) at the time of presentation. Co-morbidities were present in 89 (64.9\%) of our patients, with hypertension $51(37.2 \%)$ and diabetes mellitus $47(34.3 \%)$ been the most common. The most common symptoms were cough 71 (51.8), dyspnea 53 (38.7\%) and fever 45 (32.9). Most of the patients $69(50.3 \%)$ in our cohort were referred from lower level health facilities and majority had SPO $\leq$ $93 \% 75(54.7 \%)$. 
Table 1

Patient demographics and clinical characteristics.

\begin{tabular}{|ll|}
\hline Variables & $\mathbf{n}=137$ \\
\hline Age $(\mathbf{y})$ & $60(19-100)$ \\
\hline Age Group & \\
\hline$<29$ & $15(10.9)$ \\
\hline $29-49$ & $27(19.7)$ \\
\hline$\geq 50$ & $95(69.3)$ \\
\hline Sex & \\
\hline Male & $86(62.8)$ \\
\hline Female & $51(37.2)$ \\
\hline Medical history & \\
\hline Co-morbidities & $89(64.9)$ \\
\hline Hypertension & $51(37.2)$ \\
\hline Diabetes Mellitus & $47(34.3)$ \\
\hline Tuberculosis/COPD & $7(5.1)$ \\
\hline Chronic renal failure & $4(2.9)$ \\
\hline Congestive Heart Failure & $2(1.5)$ \\
\hline HIV & $4(2.9)$ \\
\hline Clinical features & $75(54.7)$ \\
\hline Fever & $51(22.6)$ \\
\hline Generalised body pains & $5(3.7)$ \\
\hline Sore throat & $71(51.8)$ \\
\hline Cough & $53(38.7)$ \\
\hline Dyspnea & $17.4)$ \\
\hline Chest pain & \\
\hline OXYGEN SATURATION LEVELS & \\
\hline SPO ${ }_{2} \leq 93 \%$ & \\
\hline
\end{tabular}

Data are presented as mean \pm SD or $n(\%)$. 


\begin{tabular}{|ll|}
\hline Variables & $\mathbf{n}=137$ \\
\hline $\mathrm{SPO}_{2}>93 \%$ & $62(45.3)$ \\
\hline Data are presented as mean \pm SD or $\mathrm{n}(\%)$. \\
\hline
\end{tabular}

Treatment modalities of all patients are presented in Table 2. One hundred and thirty one (96.3\%) of our patients received antibiotics, $44(32.1 \%)$ received systemic steroids and $77(56.2 \%)$ were put on supplemental oxygen therapy.

Table 2

Treatment and outcomes of 137 Covid 19 patients.

\begin{tabular}{|ll|}
\hline Variables & $\mathbf{n}=137$ \\
\hline TREATMENT & \\
\hline Antibiotics & $131(96.3)$ \\
\hline Steroids & $44(32.1)$ \\
\hline Oxygen & $77(56.2)$ \\
\hline Outcome & \\
\hline Survivor & $88(64.2)$ \\
\hline Non-Survivor & $49(35.8)$ \\
$\cdot \leq 24$ hrs & $25(54.4)$ \\
\hline
\end{tabular}

\subsection{Disease severity and hypoxemia}

Seventy five (54.7\%) and $62(45.3 \%)$ patients met the criteria for severe/critical and non-critical COVID19 associated pneumonia, respectively. Patients with SPO2 $\leq 93 \%$ were older 63.2 vs. 53.1 years $(p=0.001)$, more likely to present with dyspnea ( $50.7 \%$ vs $24.2 \%, p=0.002)$, Cough ( $60 \%$ vs $41.9 \%)$, higher respiratory rate $(25 \mathrm{cpm}$ vs. $22 \mathrm{cpm}, \mathrm{p}<0.001)$ and co-morbidities $(74.7 \%$ vs. $53.2 \%, \mathrm{p}=0.009)$ compared to patients with SPO2 $>93 \%$ (Table 3 ). 
Table 3

Characteristic differences of covid 19 patients with spo $2 \leq 93 \%$ and spo $2>93 \%$

\begin{tabular}{|c|c|c|c|}
\hline & SPO2 $\leq 93 \%(n=75)$ & SPO2 $>93 \%(n=62)$ & $\mathbf{P}$ \\
\hline Age(yrs)Mean & 63.2 & 53.1 & 0.001 \\
\hline \multicolumn{4}{|l|}{ Age groups } \\
\hline$<29$ & $4(5.2)$ & $11(17.7)$ & $<0.001$ \\
\hline $29-49$ & $5(6.7)$ & $22(35.5)$ & \\
\hline$\geq 50$ & $66(88)$ & $29(46.8)$ & \\
\hline \multicolumn{4}{|l|}{ Symptoms } \\
\hline Fever & $24(32)$ & $21(33.9)$ & 0.816 \\
\hline Generalised body pain & $14(18.7)$ & $17(27.4)$ & 0.223 \\
\hline Cough & $45(60)$ & $26(41.9)$ & 0.035 \\
\hline Dyspnea & $38(50.7)$ & $15(24.2)$ & 0.002 \\
\hline Chest pain & $11(14.7)$ & $6(9.7)$ & 0.378 \\
\hline \multicolumn{4}{|l|}{ Vital signs } \\
\hline Pulse & 108(61-171) & $103(58-177)$ & 0.463 \\
\hline Temperature $\left({ }^{0} \mathrm{C}\right)$ & $36.3(32-39.8)$ & $36.6(32-38.9)$ & 0.326 \\
\hline Systolic blood pressure (mmHg) & $122(75-193)$ & $120(72-224)$ & 0.490 \\
\hline Diastolic blood pressure $(\mathrm{mmHg})$ & $80(46-116)$ & $78.5(41-140)$ & 0.619 \\
\hline Respiratory rate & $25(14-70)$ & $22(18-34)$ & $<0.001$ \\
\hline \multicolumn{4}{|l|}{ Medical history } \\
\hline Co-morbidities & $56(74.7)$ & $33(53.2)$ & 0.009 \\
\hline Hypertension & $36(48)$ & $15(24.2)$ & 0.004 \\
\hline Diabetes Mellitus & $25(33.3)$ & $22(35.5)$ & 0.792 \\
\hline \multicolumn{4}{|l|}{ Treatment } \\
\hline Antibiotics & $72(96)$ & $59(96.7)$ & 0.824 \\
\hline Steroid use & 25 (33.3) & $19(30.6)$ & 0.737 \\
\hline Oxygen therapy & 65 (86.7) & $10(16.9)$ & $<0.001$ \\
\hline
\end{tabular}

\subsection{Survival analysis and outcome}


Our cumulative mortality was 49 (35.8\%), of which 25 (54.4\%) died $\leq 24 \mathrm{hrs}$ after admission (Table 2 ) and the median duration from admission to dead is 1 day (1-18days). Death within 24 hrs was significantly associated with lower oxygen saturation $(68 \%$ vs $93 \%, p=0.028)$ and about $88 \%$ of the patients who died within 24 hrs had Spo $\leq 93 \%$. Non survivors were older 63.2 vs 53.1 years $(p=0.001)$, more likely to present with higher respiratory rate $(25 \mathrm{cpm}$ vs $22 \mathrm{cpm}, \mathrm{p}=0.014)$, lower oxygen saturation $(73.5 \%$ vs $95.5 \%, p=<0.001)$, to be referred from a lower level health facility $(68.1 \%$ vs $31.9 \%, p=0.012)$ and to have Diabetes mellitus ( $48.9 \%$ vs $26.1 \%, p=0.007$ ) as compared to survivors (Table 4 ). 
Table 4

Characteristic differences of Covid 19 survivors and non-survivors

\begin{tabular}{|c|c|c|c|}
\hline & Survivors $(n=88)$ & Non-Survivors $(n=49)$ & p \\
\hline $\operatorname{Age}(y)$ & 53.1 & 63.2 & 0.001 \\
\hline \multicolumn{4}{|l|}{ Age groups } \\
\hline$<29$ & $13(14.8)$ & $2(4.1)$ & 0.002 \\
\hline $29-49$ & $23(26.1)$ & $4(8.2)$ & \\
\hline$\geq 50$ & $52(59.1)$ & $43(87.8)$ & \\
\hline $\operatorname{Sex}(M: F)$ & 60 (68.2): 28 (31.8) & $26(53.1): 23(46.9)$ & 0.079 \\
\hline \multicolumn{4}{|l|}{ Clinical features } \\
\hline Fever & 28(31.8) & $17(34.7)$ & 0.731 \\
\hline Generalised body pain & $24(27.3)$ & $7(14.3)$ & 0.082 \\
\hline Cough & $49(55.7)$ & $22(44.9)$ & 0.226 \\
\hline Dyspnea & $32(36.4)$ & $21(42.9)$ & 0.454 \\
\hline Chest Pain & $14(15.9)$ & $3(6.1)$ & 0.096 \\
\hline \multicolumn{4}{|l|}{ Vital signs } \\
\hline Pulse & $105(58-177)$ & $108(61-166)$ & 0.166 \\
\hline Respiratory rate & $22(18-42)$ & $25(14-70)$ & 0.014 \\
\hline Systolic Blood pressure & $120(72-224)$ & $124(75-193)$ & 0.305 \\
\hline Diastolic Blood pressure & $80(41-140)$ & $79(46-116)$ & 0.975 \\
\hline Oxygen Saturation (\%) & $95.5(28-100)$ & $73.5(43-99)$ & $<0.001$ \\
\hline SPO2 $\leq 93 \%$ & $38(43.2)$ & $37(75.5)$ & $<0.001$ \\
\hline \multicolumn{4}{|l|}{ Medical history } \\
\hline Co-morbidities & $49(55.7)$ & $40(81.6)$ & 0.002 \\
\hline Hypertension & $28(31.8)$ & $23(46.9)$ & 0.079 \\
\hline Diabetes Mellitus & $23(26.1)$ & $24(48.9)$ & 0.007 \\
\hline \multicolumn{4}{|l|}{ Treatment } \\
\hline Oxygen therapy & $38(44.2)$ & $37(77.1)$ & $<0.001$ \\
\hline Steroid use & $32(36.4)$ & $12(24.5)$ & 0.154 \\
\hline
\end{tabular}




\begin{tabular}{|lccc|}
\hline & Survivors $(\mathrm{n}=\mathbf{8 8})$ & Non-Survivors $(\mathrm{n}=49)$ & $\mathrm{p}$ \\
\hline Antibiotics & $85(96.6)$ & $46(95.8)$ & 0.822 \\
\hline Referrals & & & \\
\hline Lower level health facilities & $37(45.1)$ & $32(68.1)$ & 0.002 \\
\hline
\end{tabular}

Mortality rate of patients referred from lower level heath facilities was $46 \%$ as compared to $25 \%$ for self referred patients. Thirty five (69.4\%) of the non-survivors were 60 years or older and mortality also increased with age.

Multivariate analysis showed increasing odds of mortality independently associated with Age $\geq 60$ years (odd ratio, 2.87: $95 \% \mathrm{Cl}, 1.21$ to $6.83, \mathrm{p}=0.012$ ), Diabetes mellitus (odd ratio, 3.47: $95 \% \mathrm{Cl}, 1.44$ to $8.36, \mathrm{p}$ $=0.006$ ), oxygen saturation $\leq 93 \%$ (odd ratio, $3.18: 95 \% \mathrm{Cl}, 1.27$ to $7.99, \mathrm{p}=0.014$ ) and referral from lower level health facility (odd ratio, $2.87: 95 \% \mathrm{Cl}, 1.11$ to $6.82, \mathrm{p}=0.017$ ) (Table 5).

Table 5

Risk factors associated with death

\begin{tabular}{|lllll|}
\hline & Univariate & $\begin{array}{l}\text { p } \\
\text { value }\end{array}$ & Multivariate & p value \\
\hline Age $\geq 60$ years & $3.12(1.49-6.55)$ & 0.003 & $2.877(1.21-$ & 0.017 \\
\hline Male sex (vs Female) & $0.5(0.23-1.11)$ & 0.088 & & \\
\hline Diabetes Mellitus & $2.71(1.30-5.65)$ & 0.008 & $3.47(1.44-8.36)$ & 0.006 \\
\hline Hypertension & $1.89(0.924-3.89)$ & 0.081 & & \\
\hline $\begin{array}{l}\text { Oxygen Saturation } \leq 93 \% \text { (vs }> \\
\text { 93\%) }\end{array}$ & $4.04(1.87-8.81)$ & $<$ & $3.18(1.27-7.99)$ & 0.014 \\
\hline Respiratory rate $\geq 24$ (vs $<24)$ & $2.095(0.948-$ & 0.067 & & \\
\hline Lower level Health Facility Referral & $2.59(1.22-5.50)$ & 0.013 & $2.87(1.21-6.82)$ & 0.017 \\
(vs self-referral) & & & & \\
\hline Oxygen therapy & $4.25(1.92-9.42)$ & $<$ & & \\
\hline Corticosteroid use & $0.57(0.26-1.24)$ & 0.156 & & \\
\hline
\end{tabular}

\subsection{Discussion}


We present this retrospective study that describes the clinical characteristics of 109 patients with COVID19 admitted in EFSTH, a tertiary teaching Hospital in The Gambia. It provides additional insight into the risk factors for COVID-19 mortality in moderate to critically ill patients with COVID 19 associated pneumonia in resource limited countries. As in previous studies, our study has confirmed that age, comorbidities especially Diabetes Mellitus as important prognostic factors associated with mortality in COVID 19 patients. We further report clinically important prognostic risk factors that are independently associated with mortality in our cohort: Hypoxemia (spo2 $\leq 93 \%$ ) and patients referred from lower level health facilities.

The demographics of our patients were consistent with other studies. Males were more affected, and much older at presentation compared to females(7)'(14). Most of our patients were also elderly with comorbidities, hypertension and Diabetes mellitus being the most common(2)'(15)'(16)'(17). As confirmed in other studies(3)'(7)'(18)'(19), increasing age and Diabetes Mellitus were important prognostic factors associated with mortality in our patients. In contrast, $69.4 \%$ of deaths occurred at 60 years or older in our cohort as compared to $80 \%$, or more in these other studies. This difference could be due to the very young age in West Africa(3)'(10) (64\% under the age of 24 years) compared to the develop world. Despite having a young population, the Gambia also has other risk factors similar to European countries ( $27 \%$ of Gambians have hypertension and $6 \%$ have diabetes) which further increases the risk of severe forms of COVID-19 and mortality(15).

The most commonly reported symptoms in our cohort were cough, dyspnea and fever at the time of presentation which is similar to other studies(20)(21)(22). However, fever was not the most common symptom at presentation. As already known, cough and dypsnea are the most common symptoms in the late phase of the disease which also coincides with the severe phase and also the onset of complications(23). This confirms the fact that most of the patients in our cohort presented late with either a severe disease or a complication of COVID 19.Therefore using a case definition requiring fever and at least one respiratory symptom may lead to an under diagnosis of a substantial proportion of patients with severe Covid 19(22) in The Gambia. Whether this finding in our cohort is due to the severity of the disease at presentation and/ or age of our patients, further research is needed to answer this question.

Most of our patients were referred from lower level health facilities. However, self referred patients had a better prognosis as compared to those referred from lower level health facilities. As already known, stigmatization negatively affects people in seeking and accessing health care(24)during pandemics. Study done in adult Gambian population also showed high level of worry and fear related to Covid19(25). Further delay in lower level health facilities and the lack of critical care resources in these facilities could therefore result in worsening of patient's condition before referring to a tertiary level. These important findings suggest that factors responsible for delay in referring patients in our lower level health facilities must be identified and addressed. As already stated in the 2012-2020 national health policy of The Gambia, some of the challenges of referring patients include inadequate number of ambulances, intermittent shortage of fuel, inadequate capacity to manage cases effectively, inadequate feedback 
mechanism, inadequate referral protocol and guidelines and late referrals especially at community level. Other factors that could have contributed to late referrals included the delay in receiving COVID 19 results from the central testing centre, and the non-availability of sample collectors in some health facilities.

Majority of our Patients presented with SPO2 of $\leq 93 \%$. These patients were older, more likely to present with co-morbidities, respiratory features and more likely to be non-survivors. About $90 \%$ of the patients who died within $24 \mathrm{hrs}$ also had Spo $2 \leq 93 \%$ and death within $24 \mathrm{hrs}$ was significantly associated with Spo $2 \leq 93 \%$. On subgroup analysis, $70 \%$ of patients with 60 years or older who had increased risk for mortality had SPO2 of $\leq 93 \%$. Despite supplemental oxygen, oxygen saturation of $\leq 93 \%$ was independently associated with death in our patients. Similar findings were found in other studies(26)'(27) but at a lower level of oxygen saturation. This easily acquired clinical measure provides a more robust risk factor for fatal outcomes of patients with COVID 19 and thus should be part of our health system priority list. These findings of hypoxemia as an important prognostic factor for hospitalised patients with COVID 19 pneumonia in our cohort justifies the need to: 1) provide reliable supply of oxygen and its consumables (e.g. Nasal cannula, simple face mask, non-rebreathing mask), 2) set up and implement treatment guidelines on the use of oxygen, and 3) train health workers on the importance of oxygen therapy and modalities involved in giving oxygen.

Non survivors in our study were older, more likely to present with higher respiratory rate, lower oxygen saturation and Diabetes mellitus compared to survivors. This study confirms the fact that non-survivors were more likely to have severe disease and predictors of poor outcome(26). Approximately $35.8 \%$ of our patients died of COVID 19. This is high when compared with patients admitted due to pneumonia (8.7$21 \%)(4)^{\prime}(5) \cdot(6)$ but is lower when compared with critically ill patients $(49 \%)(7)$. The reason for this mortality may be that those who have a severe COVID 19 disease (54.7\% in our study) are the ones likely to present to a tertiary health care facility as compared to the mild or asymptomatic cases. Majority of deaths occurred within $24 \mathrm{hrs}$ of admission and the median duration from admission to death is 1 day (1-18 days). The duration of hospital stay for non-survivors was similar to a study done in Nigeria(26) but much shorter compared to other studies(28). Death within $24 \mathrm{hrs}$ was also significantly associated with lower oxygen saturation. This further confirms the need for supplemental oxygen as a first essential step for the treatment of patients with severe COVID-19 and should be a primary focus in The Gambia.

Further subgroup analysis, also indicates that mortality rate of patients referred from lower level heath facilities was higher ( $46 \%$ vs $25 \%$ ) as compared to self referred patients. This further confirms the fact that the lack of critical care resources, poor referral system and delay in COVID 19 testing in the lower level health facilities may have an impact on the outcome of COVID 19 patients in The Gambia.

This study has some limitations. First, as COVID 19 is a new disease and not much was known about the disease at the beginning of the pandemic, limited laboratory and radiologic investigations were done for our patients. Therefore, their role might be underestimated in predicting mortality. Secondly, Lack of effective antiviral, inadequate adherence to standard supportive therapy, and high-dose corticosteroid use might have also contributed to the poor clinical outcomes in some patients. Lastly, interpretation of our

Page 15/19 
findings might be limited by the sample size. Even with its limitations, the results presented in this article are similar to the world literature but has found delay in primary and secondary health facilities as an important prognostic factor in low resource settings.

\subsection{Conclusion}

The above findings confirms the fact that each countries survival data maybe different. Most independent variables (Age $\geq 60$ years and Diabetes Mellitus) associated with survival that we identified in our cohort have also been identified in other studies. However, hypoxemia and referral from lower level health facilities may have been unique, important prognostic factors of severe COVID 19 patients in The Gambia. These patients who are at risk of becoming critically ill or dying should therefore be identified early and maximal care given during the acute illness. There is also need to improve the critical care/ emergency units of the lower level health facilities, National referral system and testing facilities to help avoid delay in referring Covid 19 patients to tertiary facilities.

\subsection{Declarations}

Ethics approval and consent to participate: Ethical approval for the study was obtained from the University of The Gambia Research and Publication Committee (REPUBLIC) and all methods were performed in accordance with the relevant guidelines and regulations. The rationale, questions, methodology, case-note review, data collection, anonymization, data security and analysis were all appropriate for the study and no ethical issues were raised. Informed consent waiver was obtained from the REPUBLIC.

Consent for publication: Not Applicable.

Availability of data and materials: The datasets generated and/or analysed during this study are included in this published article (and its supplementary information file)

Competing interests: The authors declare that they have no competing interests.

Funding: No funding was received for this study

Authors contribution: Contributors roles: SOB : Conceptualising, Data curation, Formal analysis, Investigation, Methodology, Project administration, Resources, Software, Supervision, Validation, Visualization, Writing-original draft, Writing-review and editing; AJ and AB : Conceptualising, Data curation, Supervision, Writing-review and editing ; BF and EB : Data curation, Investigation, Supervision; IS, MRD, RS, LJ, GG, MC, SS, SJ, MS, MD, WE, JAP, FCM, MASA : Data curation, Supervision ; CR, MB, AS:

Conceptualising, Supervision, Writing - Original draft; RN and ON: Conceptualising, Supervision, Visualisation, Writing - Original draft, Writing - Review \& Editing. 
Acknowedgements: We thank Fanta Sisawo and Fatou Ceesay of the EFSTH records office for helping in the data collection.

\section{References}

1. Umviligihozo G, Mupfumi L, Sonela N, Naicker D, Obuku EA, Koofhethile C, et al. Sub-Saharan Africa preparedness and response to the COVID-19 pandemic: A perspective of early career African scientists. Wellcome Open Res. 2020;5:1-20.

2. Lone SA, Ahmad A. COVID-19 pandemic - an African perspective. 2020;9.

3. Tinto B. Spreading of SARS-CoV-2 in West Africa and assessment of risk factors. 2020;1-9.

4. Suleyman G, Fadel RA, Malette KM, Hammond C, Abdulla H, Entz A, et al. Clinical Characteristics and Morbidity Associated With Coronavirus Disease 2019 in a Series of Patients in Metropolitan Detroit. JAMA Netw open. 2020;3(6):e2012270.

5. Sousa GJB, Garces TS, Cestari VRF, Florêncio RS, Moreira TMM, Pereira MLD. Mortality and survival of COVID-19. Epidemiol Infect. 2020;148:e123.

6. Yang S, Cao P, Du P, Wu Z, Zhuang Z, Yang L, et al. Early estimation of the case fatality rate of COVID19 in mainland China: a data-driven analysis. Ann Transl Med. 2020;8(4):128-128.

7. Ramanathan K, Antognini D, Combes A, Paden M, Zakhary B, Ogino M, et al. Since January 2020 Elsevier has created a COVID-19 resource centre with free information in English and Mandarin on the novel coronavirus COVID- research that is available on the COVID-19 resource centre - including this for unrestricted research re-use a. 2020;(January):19-21.

8. Sousa GJB, Garces TS, Cestari VRF, Florêncio RS, Moreira TMM, Pereira MLD. Mortality and survival of COVID-19. Epidemiol Infect. 2020;1-6.

9. Stein F, Perry M, Banda G, Woolhouse M, Mutapi F. Oxygen provision to fight COVID-19 in subSaharan Africa. BMJ Glob Heal. 2020;5(6):1-4.

10. Ogunleye OO, Basu D, Mueller D, Sneddon J, Seaton RA, Yinka-Ogunleye AF, et al. Response to the Novel Corona Virus (COVID-19) Pandemic Across Africa: Successes, Challenges, and Implications for the Future. Front Pharmacol. 2020;11(September):1-36.

11. Touray S, Sanyang B, Zandrow G, Dibba F, Fadera K, Kanteh E, et al. An assessment of critical care capacity in the Gambia. J Crit Care [Internet]. Elsevier Inc.; 2018;47:245-53. Available from: https://doi.org/10.1016/j.jcrc.2018.07.022

12. Out of Hospital Emergency Outcomes_Touray_et_al2018.pdf.

13. WHO. WHO COVID-19 Case definition Suspect COVID-19 case Confirmed COVID-19 case. 2020; (August):2020.

14. Huang C, Wang Y, Li X, Ren L, Zhao J, Hu Y, et al. Clinical features of patients infected with 2019 novel coronavirus in Wuhan, China. Lancet. 2020;395(10223):497-506.

15. Martinez-Alvarez M, Jarde A, Usuf E, Brotherton H, Bittaye M, Samateh AL, et al. COVID-19 pandemic in west Africa. Lancet Glob Heal [Internet]. The Author(s). Published by Elsevier Ltd. This is an Open 
Access article under the CC BY-NC-ND 4.0 license; 2020;8(5):e631-2. Available from: http://dx.doi.org/10.1016/S2214-109X(20)30123-6

16. Anjorin AA, Abioye Al, Asowata OE, Soipe A, Kazeem MI, Adesanya IO, et al. Comorbidities and the COVID-19 pandemic dynamics in Africa. 2020;00(00):1-12.

17. Boulle AA, Davies M, Hussey H, Morden E, Vundle Z, Zweigenthal V, et al. Risk factors for COVID-19 death in a population cohort study from the Western Cape Province, South Africa. :1-31.

18. Surveillances V. The Epidemiological Characteristics of an Outbreak of 2019 Novel Coronavirus Diseases ( COVID-19) - China , 2020. 2020;2(x):1-10.

19. Report MW. Severe Outcomes Among Patients with Coronavirus Disease 2019 ( COVID-19) - United States , February 12 - March 16, 2020. 2020;69(12):343-6.

20. Song J-Y, Yun J-G, Noh J-Y, Cheong H-J, Kim W-J. Covid-19 in South Korea - Challenges of Subclinical Manifestations. N Engl J Med. 2020;382(19):1858-9.

21. Rodriguez-Morales AJ, Cardona-Ospina JA, Gutiérrez-Ocampo E, Villamizar-Peña R, Holguin-Rivera $Y$, Escalera-Antezana JP, et al. Clinical, laboratory and imaging features of COVID-19: A systematic review and meta-analysis. Travel Med Infect Dis. 2020;34(January).

22. Guan W, Ni Z, Hu Y, Liang W, Ou C, He J, et al. Clinical Characteristics of Coronavirus Disease 2019 in China. N Engl J Med. 2020;382(18):1708-20.

23. Fei Zhou*, Ting Yu* RD et al, Lancet. Clinical course and risk factors for mortality of adult inpatients with COVID-19 in Wuhan, China: a retrospective cohort study. 2020;(January):19-21.

24. Bruns DP, Kraguljac NV, Bruns TR. COVID-19: Facts, Cultural Considerations, and Risk of Stigmatization. J Transcult Nurs. 2020;31(4):326-32.

25. Lowe M. Examining the perceptions and behaviors of gambian adults in response to COVID-19 social mitigation strategies. Pan Afr Med J. 2020;37(238):1-6.

26. Ibrahim OR, Suleiman BM, Abdullahi SB, Oloyede T, Sanda A, Gbadamosi MS, et al. Epidemiology of COVID-19 and Predictors of Outcome in Nigeria: A Single-Center Study. 2020;103(6):2376-81.

27. Ruan Q, Yang K, Wang W, Jiang L, Song J. Clinical predictors of mortality due to COVID - 19 based on an analysis of data of 150 patients from Wuhan , China. Intensive Care Med [Internet]. Springer Berlin Heidelberg; 2020;46(5):846-8. Available from: https://doi.org/10.1007/s00134-020-05991-x

28. Rees EM, Nightingale ES, Jafari Y, Waterlow NR, Clifford S, Pearson CAB, et al. COVID-19 length of hospital stay: a systematic review and data synthesis. BMC Medicine; 2020;

\section{Figures}




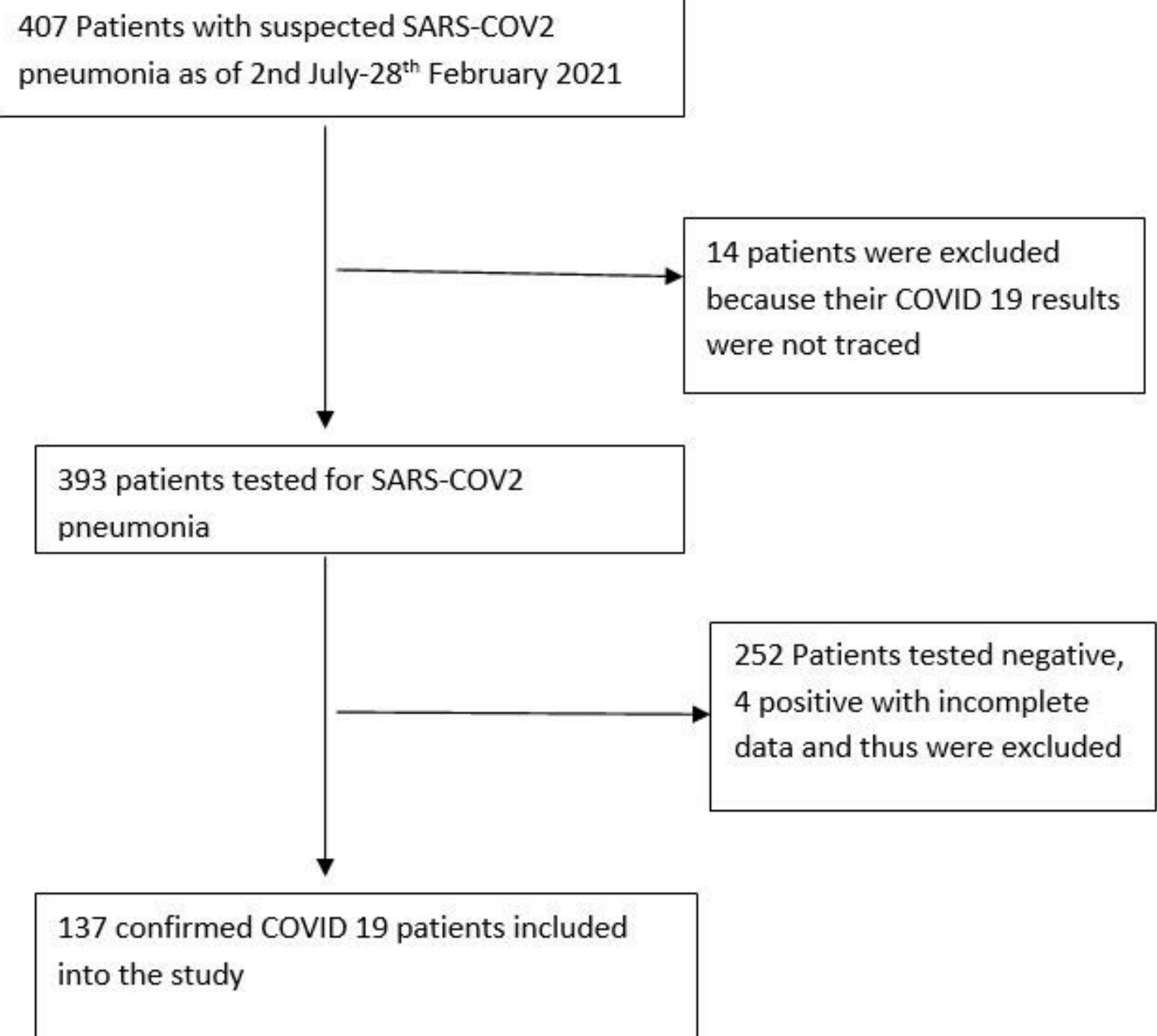

Figure 1

Study flow diagram

\section{Supplementary Files}

This is a list of supplementary files associated with this preprint. Click to download.

- EFSTHCOVID19DATAWITHDICTIONARY.xIs 